\title{
Industrial Control System of Roll Stamping
}

\author{
Aleksandr Pilipenko ${ }^{1, *}$, Anastasia Pilipenko ${ }^{1}$, and Olga Pilipenko ${ }^{1}$ \\ ${ }^{1}$ Federal State Budgetary Educational Institution of Higher Education «Orel State University named after I.S. Turgenev», Department of \\ Automated Control Systems and Cybernetics, Orel, Russia
}

\begin{abstract}
The article describes approaches to the automation of roll stamping. Authors deeply cover aspects of design of the hardware and PID controller. In the article authors represent algorithms of the existing automated system and examples of use of machine vision for solving of application-oriented tasks.
\end{abstract}

\section{Introduction}

Now a priority task for the industrial enterprises is the release of competitive production with the minimum expenses. Production of products and details by methods of form changing operations is characterized by profitability of consumption of metal, an opportunity to receive details of high precision with high technical characteristics. Rather new development of these methods is the technology of plastic processing of metals with complex local loading of a billet which received the name "roll stamping" [1,2,3]. Roll stamping combines in a single technological process operations of volume stamping and local deforming by not drive or drive rolls. The technique of roll stamping is applied in practice to receive solid and hollow details, thin-walled products of small sizes with high accuracy and quality of manufacture with the technological force much smaller, than for traditional methods of volume stamping. Roll stamping found its classical application in the field of production of axisymmetric cylindrical details of high accuracy including multistage ones.

The diagram of process of roll stamping is carried out as follows (Figure 1): forming of billet 1 is made in the roller matrix including the rotating stop 2 and formbuilding rollers 5 , punch 3 and besides punch 3 and stop 2 rotate together with billet 1 with angular speed $\omega 1$, and rotation of rollers 5 is carried out with angular speed $\omega 2$, connected with $\omega 1$ through a ratio of diameters of rollers 5 and detail, and rotation of billet 1 is carried out at the expense of forces of contact friction with rollers 5. On a line item of roll stamping two operations are executed at the same time. The first one is piercing or forming of billet 1 by punch 3 with force $P$, the second one is rolling of billet 1 on an outside circuit by rollers 5. Punch 3 makes the working course down to complete shaping of billet 1.Use a two-column format, and set the spacing between the columns at $8 \mathrm{~mm}$. Do not add any page numbers.

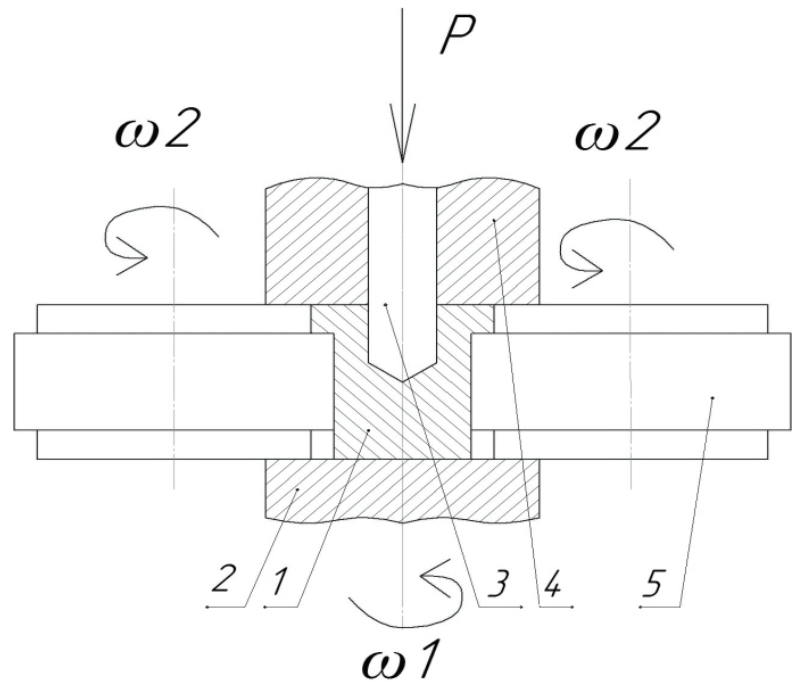

Fig. 1. Scheme of process of roll stamping.

The classical equipment for roll stamping is the hydraulic press and die tooling. A large number of scientific and technical works is devoted to automation of hydraulic press. However, automated process control systems of roll stamping are not practically mentioned anywhere. It should be taken into account that technological processes of roll stamping last from several hours to several days, demand obligatory participation of the operator for control of accuracy, speed of rotation of rolls or a billet, subcontrol. [3] Taking all this into account, it is possible to assume that development of an automated control system for nonstationary technological process with intellectual algorithms of computer modeling and machine vision is a new relevant task.

\section{Conception}

In technological processes of roll stamping it is necessary not only to give to a product the required geometry and to create a certain microstructure of material, but also to provide stable repeatability of result

\footnotetext{
* Corresponding author: a@pilipenko.info
} 
of operation of the equipment when unsteady, long duration and danger of technological processes of deformation. This problem is solved by the created modern system of the automated management of the lower level, capable to analyze big amounts of information from sensors in the confidant to real time mode. Use of machine vision for identification of reject during its emergence expands possibilities of system. The following requirements to the developed system of automated management are formulated $[4,5]$ :

- processing of information from sensors, visualization of the processed information;

- creation of computer imitating model of process of roll stamping;

- analysis of operation of the equipment on the basis of comparison of information from sensors and from computer model;

- recommendations about selection of optimum working parameters;

- self-diagnostics;

- convenient display of all information for the operator;

- a possibility of work in the automatic mode;

- a possibility of the analysis of emergence of reject during processing.

\subsection{Design}

According to the created requirements the specification of the equipment of management system of technological process of forming, executed on the hydropress equipment was developed. And authors tried to make system most unified and suitable for any hydropress equipment therefore NICompactRIO was selected as a controller [6]. It is a worthy modular industrial controller with the modern icore processor having onboard necessary quantity of analog and digital inputs and outputs and also the buses Ethernet, RS-485 and RS-285, and working with the standard TCP/IP, Modbus and Can protocols. The panel of manual control set on a hydraulic press is connected to the industrial controller via the bus RS-485. Via the bus Ethernet remote system management through a Web server is provided. [7] Stepping motors with reducers for control of throttles and also the frequency transformers for management of engine pump and the equipment engine which rotates rolls are connected to digital outputs. Sensors of relocation, pressure, density of pressure fluid, etc. are connected to analog inputs of the device.

The generalized structure of management system is provided in figure 2. In an automatic mode of operation the PC controller sets starting values $x(t)=p 0(t), x 0(t)$, $v 0(t)$, influencing rotating speed of the engine of the hydraulic pump $\omega$ and the expenditure of the liquid passing through the throttle $q$. The sensors set on a hydraulic press, measuring parameters on the unit of a self-adjustment which, comparing the data obtained experimentally and by computer simulation calculates the adjusting coefficient $k_{a d j}$, using the logical law of control: if $\left|p_{\text {exp }}\right|<0,2 *\left|p_{\text {mat }}\right|$, then $k_{\text {adj }}=p_{\text {exp }} * k_{l}$; otherwise $k_{a d j}=p_{\text {exp }} * k_{2}$; where $k_{1}<k_{2}$. Regulator creates controlling influence $U(t)$ and transfers it to used controller.

The novelty of management system consists in the developed principle of combined control integrating the principle of control on a deviation and the logical nonlinear law of control.

At the same time by the principle of control on a deviation the system is described by transfer function of open-ended system and the equation of closing: $x(t)=g(t)-y(t) \operatorname{Woc}(p)$. The algorithm of system operation is in the aspiration to reduce an error $x(t)$ to zero.

One of advantages of such a diagram is that feedback leads to reduction of an error irrespective of factors having caused it (changes of parameters of an adjustable object or external conditions).

Non-linear laws of control can have other forms which are implemented by means of not functional but more or less difficult logic devices. We will call them logical non-linear algorithms. In a system logical nonlinear algorithm is applied to save controlling impacts on an object (and also saving of power consumption for needs of control).

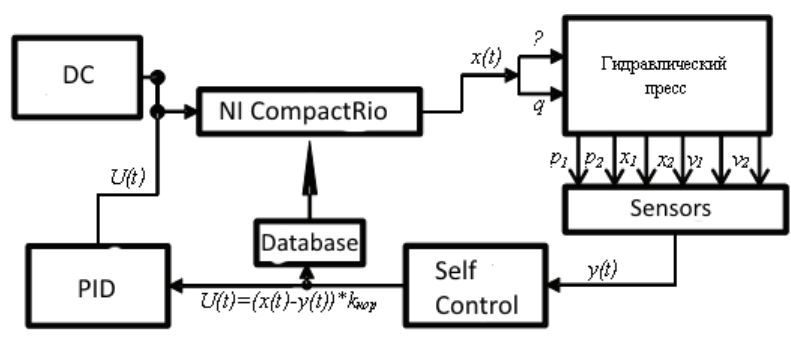

Fig. 2. The generalized structure of a control system.

\subsection{Modelling and regulation}

Subject to regulation in this system is the valve of a throttle and the frequency converter which regulates a hydraulic pump engine speed. It should be taken into account that there is a computer model which specifies desirable movement of a traverse depending on the current pressure $[8,9,10,11]$. The condition of an object is defined by: 1) pressure; 2) movement. The operator model of a control system is presented in figure 3 .

Having carried out synthesis of system of regulation by a throttle and system of regulation by frequency converters complex regulation of pressure in a general view is received:

$$
\begin{gathered}
W o p=\frac{k * e^{\tau_{B O} * P}}{T_{B O} * p+1}+\frac{k_{n u-\partial}}{T_{m} p+1} * \frac{k_{H}}{T_{H} p+1} \\
W o p=\frac{k_{n u-\partial} k_{n} T_{B O} * p+k_{n u-\partial} k_{n}+k * e^{\tau_{B O} * P} T_{m} p^{2} T_{u} p+k * e^{\tau_{B O} * P} T_{m} p+k * e^{\tau_{B O} * P} p T_{n} p+k * e^{\tau_{B O} * P}}{\left(T_{B O} * p+1\right) *\left(T_{m} * p+1\right) *\left(T_{n} * p+1\right)}
\end{gathered}
$$




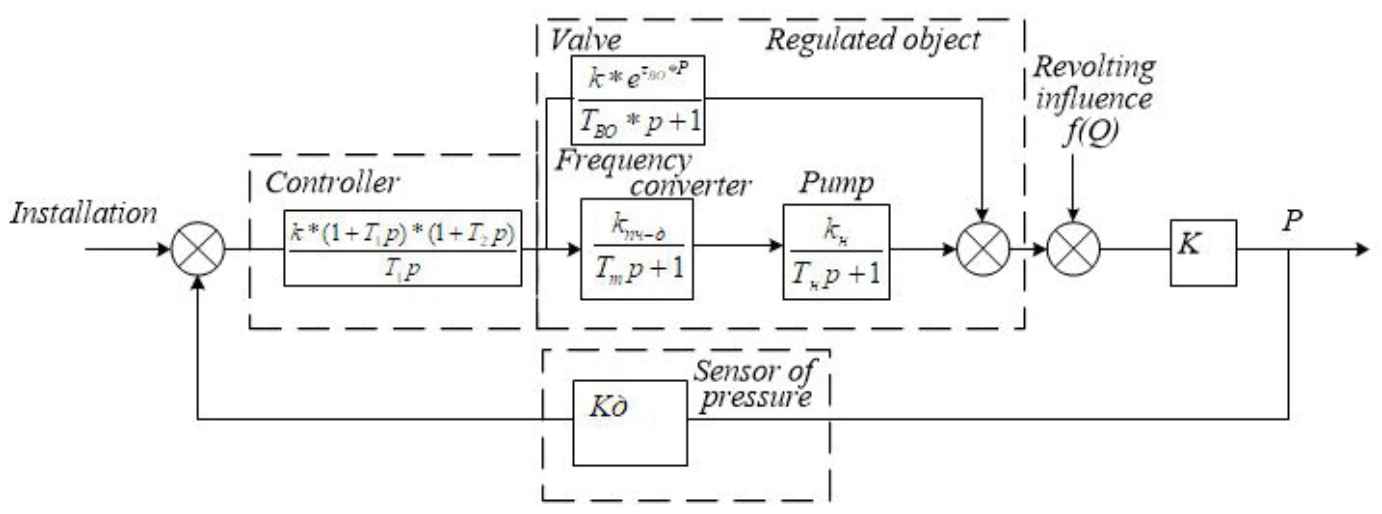

Fig. 3. Operator model of an automation object. A valve; a regulated object; the revolting influence; a controller; a setpoint; a frequency converter; a pump; a sensor of pressure.

So, we will admit: Pressure $(t)$ - current pressure in the pressure head trunk (a present situation of time t), Relocation $(t)$ - current relocation. Also we have a Step $(t)$ - current step of a throttle, Frequency $(t)$ - rotating speed of the engine of a hydraulic pump and Pressure $(t+1)$ - new value of engine speed which depends on temperature. It is necessary to receive as a result Step $(t+1)$ - new position of the throttle and Frequency $(t+1)$ - new frequency of the engine:

Step $(t+1)=$ Function $\{$ Step $(t)$, Pressure $(t)$, Relocation ( $t)$, Pressure $(t+1)\}$

Frequency $(t+1)=$ Function $\{$ Step $(t+1)$, Frequency $(t)$, Pressure $(t)$, Relocation $(t)$, Pressure $(t+1)\}$

The first function gives the current value of a step which depends on all above-mentioned, and the second gives the current frequency rate.

It is necessary to know value of the current error (discrepancy), and it can be calculated as the difference of estimated pressures in the future and current ones:

Error $(t)=$ Pressure $(t+1)-$ Pressure $(t)$

In case pressure accurately corresponds to required one the error will be equal to zero. This error shows how strong influence shall be. The formula for the following step can be written as follows now:

Step $(t+1)=$ Function $\{$ Step $(t)$, Error $(t)\}$

Now it is possible to put value of the previous step outside brackets:

Step $(t+1)=$ Step $(t)+$ Function $\{$ Error $(t)\}$

On each step of regulator operation current position of the stepping motor is set. The stepping motor is operated by offsets therefore the current step is not so important. As a result it is possible to pass to such a record:

Change of Step $(t+1)=$ Function $\{$ Error $(t)\}$

It is a little more difficult as far as frequency is concerned since it does not make a sense to control directly two devices. As a result control of the frequency transformer (frequency change) begins only when throttle is in limit position, thus limits of control extend and accuracy increases. Function of determination of limit value of the stepping motor looks as follows:

Limit SM $(t)=$ the Step $(t+1)$ - the Step $(t)$
In case step accurately corresponds to required one, the limit of SM will be equal to zero.

Function for frequency looks as follows:

Frequency $(t+1)=$ Limit SM $(t)$ Frequency $(t)+$ Function $\{$ Error $(t)$ \}

The developed mathematical apparatus is set in the system of computer simulation (figure 4).

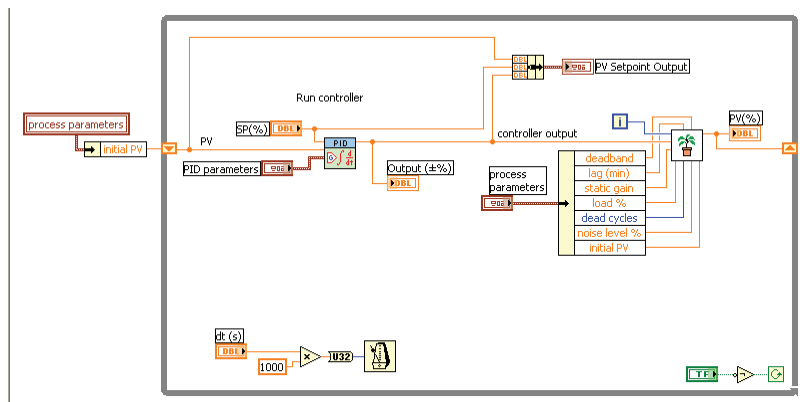

Fig. 4. The flowchart of system of regulation with use of mathematical model

At the same time, the PID controller used in the flowchart in figure 4 has its own flowchart shown in figure 5 .

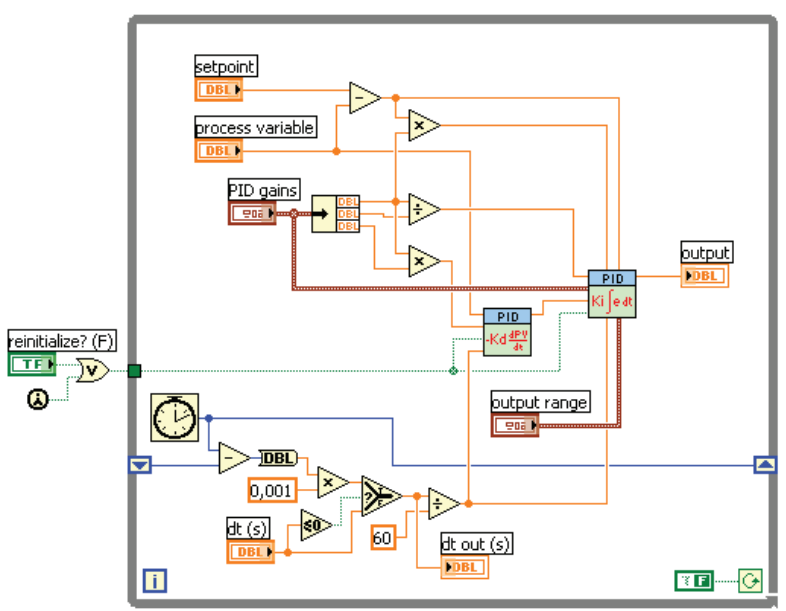

Fig. 5. Flowchart of the PID controller

\subsection{Algorithmization and programming}


The management system algorithm for the PC-controller is provided in figure 6. In it the following sequence of actions is executed:

1 - Beginning ; 2 - Input of the name of test, comment and N-quantity of the required cycles; 3 Operation mode choice: Automatic control; 4 regulator: the frequency transformer of the drive of a hydraulic pump and to move a traverse to the maximum position; 5 - regulation by throttle the frequency transformer, to move a traverse to the maximum position; 6 - Procedure of initialization of the data collecting device; 7 - Start of a subsystem of machine vision for the analysis of appearance of spoilage; $8-$ Start of the subprogram of computer simulation and PIDregulation; 9 - 13 - Material data entry: L, d, h; 14 Choice of material and its parameters; 15 - 19-Type of material, density, diagram of resistance of deformation, etc.; 20 - Choice of parameters of equipment operation; 21-25 - Parameters of regulation, pressure, speed, etc.; 26 - Data collection from ADC [12]; 27 - Data filtering; 28 - Data handling and conversion to C; 29 - Solution of differential equations with the Runge-Kutta 2 method $[13,14] ; 30$ - Output of diagrams and data to the screen; 31 - Subprogram of comparing of data; $32-\mathrm{i}=\mathrm{N}$ ?; $33-$ Do you want to change $\mathrm{N}$ of cycles and to continue work?; 34 - Detection of an error of system operation or defect of a detail. 35 - End of the program.

The code of the subprogram of detection of defects with use of machine vision $[15,16]$ is provided in figure 7.

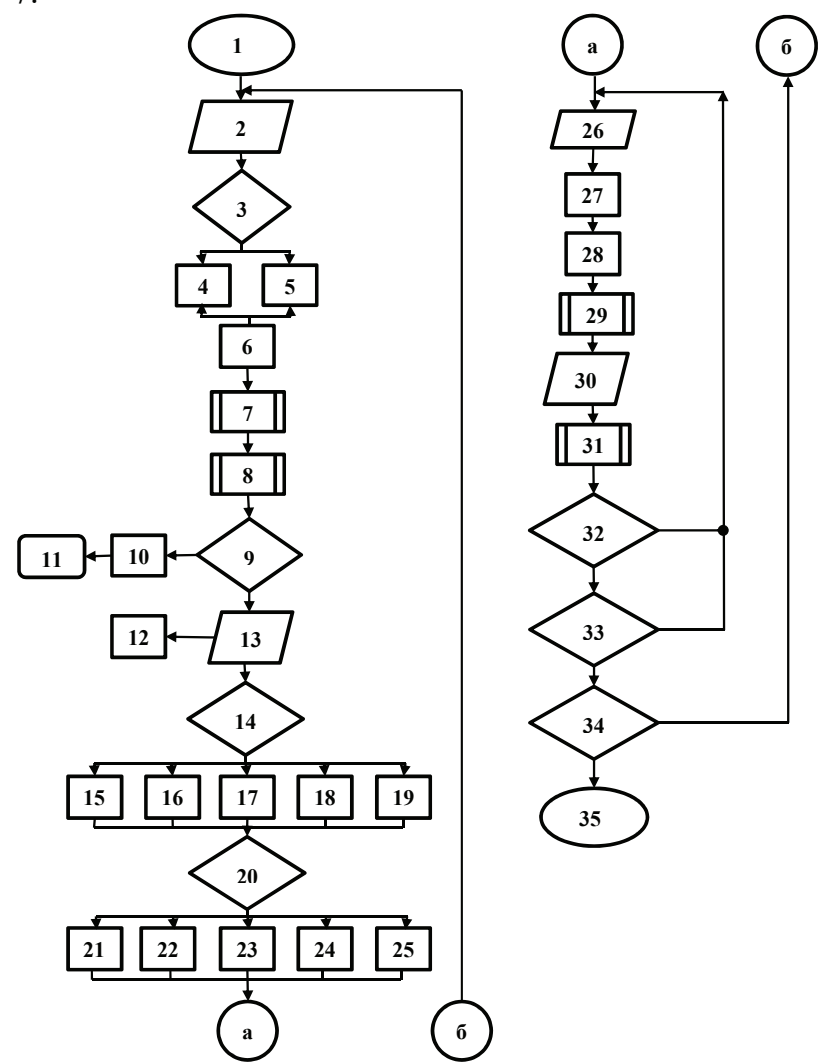

Fig. 6. An algorithm of the adaptive system of control for the PC controller

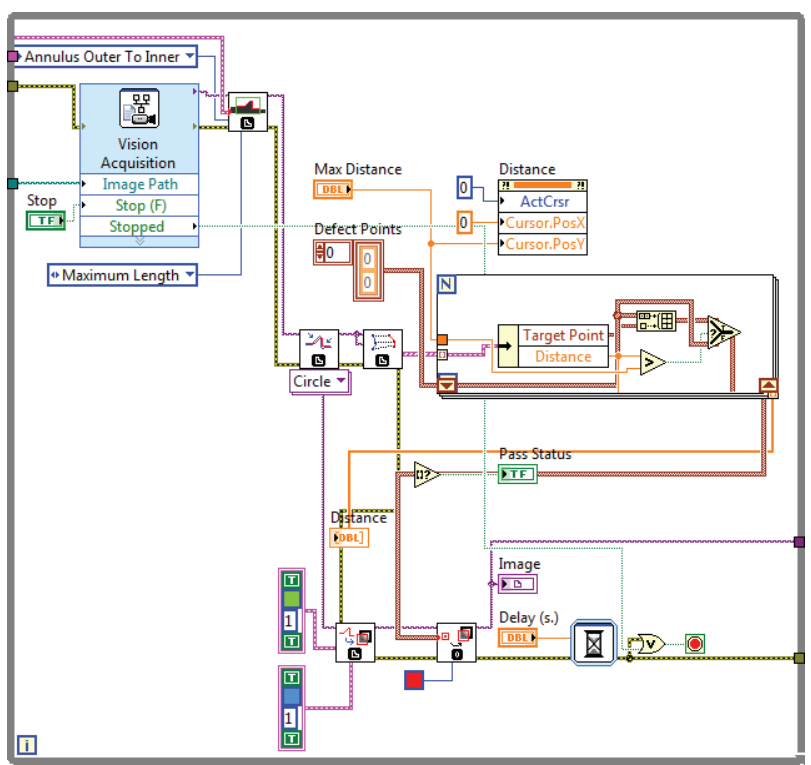

Fig. 7. Code of the subprogram of detection of defects

\section{Conclusion}

This work contains the solution of the task of development of an automated control system for the hydropress equipment on the basis of the adaptive algorithms constructed on mathematical models of dynamics of the hydropress equipment with the equipment for roll stamping. The created hardware and software system $[17,18]$ underwent approbation in the conditions of real manufacturing enterprise.

It is defined that achievement of stability of management system requires control on the PID controller $[19,20]$. The proportional component in the PID controller works at the time of appearance of a mismatch. When traverse begins to move, power begins to fall down and when reaches the minimum point the device is switched off. The effect of influence is revealed with delay. An object is also influenced by the environment: traverse mass, compressibility of liquid and pipeline. For compensating of "external" influence the integral component is added to a circuit. As a result of such approach the integral becomes stable therefore value of the given power becomes constant. For compensating of influence of time delays between influence and response of system the differential component is added to the system.

\section{References}

1. S. Radchenko, Razrabotka novyh tekhnologicheskih processov valkovoj shtampovki tonkostennyh izdelij i metodov ih proektirovaniya, Thesis for a degree of Doctor of Technical sciences, 308 (2003) [in Russian]

2. V. Golenkov, S. Radchenko, D. Dorokhov, High technologies in mechanical engineering, no. 3, 3137 (2011) [in Russian]

3. S. Teslenko, Casting and metallurgy, no. 3 (66) (2012) [in Russian] 
4. A. Pilipenko, Information systems and technologies, 4/66,115-119 (2011) [in Russian]

5. A. Pilipenko, Fundamental and application-oriented problems of technique and technology, no. 6-2 (296), 47-52 (2012) [in Russian]

6. M. Rosol, A. Pilat, A. Turnau, Computer Science and Information Technology (IMCSIT), Proceedings of the 2010 International Multiconference on. IEEE, 825-830 (2010)

7. J. Travis, J. Kring, Lab VIEW for everyone: graphical programming made easy and fun (Prentice-Hall, 2007).

8. A. Pilipenko, Certificate of registration of the computer program, No. 2011611940, 3.03.2011 (2011) [in Russian]

9. A. Pilipenko, Certificate of registration of the computer program No. 2011610002, 11.01.2011 (2011) [in Russian]

10. A. Pilipenko Certificate of registration of the computer program No. 2011614723, 16.06.2011 (2011) [in Russian]

11. A. Pilipenko Fundamental and application-oriented problems of technique and technology, No. 6-2 (296), 58-64 (2012) [in Russian]

12. D. Budanov, D. Morozov, M. Pilipko, Radio engineering and electronics, 62, No. 4, 399-410 (2017) [in Russian]

13. E. Kamke Spravochnik po obyknovennym differencial'nym uravneniyam (Publishing house "Science", Principal edition of physical and mathematical literature, Moscow, 1971), p. 576. [in Russian]

14. A. Kim, S. Polnikov, Modern innovations, No. 8, 57. (2016) [in Russian]

15. A. Pilipenko, Industrial ICS and controllers, No. 5, 39-40 (2009) [in Russian]

16. A. Pilipenko, Industrial ICS and controllers, No. 4, 63-69 (2013) [in Russian]

17. Pilipenko A. Certificate of registration of the computer program No. 2011611941, 3.03.2011. (2011) [in Russian]

18. Pilipenko A. Certificate of registration of the computer program. No. 2011611939, 3.03.2011. (2011) [in Russian]

19. Alexandrov A., Palenov M. Automatic equipment and telemechanics, No. 2, 16-30. (2014) [in Russian]

20. Chertkov A., Tormashev D., Saburov S. Bulletin of the State university of sea and river fleet named after Admiral S.O. Makarov, No. 5 (27) (2014) [in Russian] 